\title{
A semântica do lixo e o desenvolvimento socioeconômico dos catadores de recicláveis-considerações sobre um estudo de caso múltiplo em cooperativas na cidade do Rio de Janeiro
}

The semantics of garbage and the socioeconomic development of recyclable garbage gatherers - considerations about a multiple case studies in cooperatives in the city of Rio de Janeiro

Scarlet Carmo ${ }^{1}$

\section{Resumo}

Entre 2002 e 2004 foram realizados estudos de caso em três cooperativas de catadores apoiadas pelo poder público e localizadas em região de lixo rico da cidade do Rio de Janeiro, Brasil. A partir desses estudos, este artigo sugere que a semântica (negativa e positiva) do lixo seja considerada um aspecto importante quando de intervenções públicas como esta. A semântica negativa do lixo-associada à questão da sujeira_, inicialmente, considerada um obstáculo à organização dos catadores, permanece um desafio não totalmente superado. Da mesma forma, a semântica positiva também não ajuda muito a melhorar suas condições sociais e econômicas. Os desdobramentos das intervenções públicas realizadas sugerem que organizá-los em cooperativas nos moldes propostos é algo complexo, mas ao mesmo tempo imprescindível. De modo que se faz necessária uma maior interação entre ambos—poder público e catadores—, para que se possa dar conta dos paradoxos que a semântica (negativa ou positiva) do lixo representa para eles.

Palavras-chave: semântica do lixo; catadores de lixo; cooperativa; reciclagem; política pública.

\begin{abstract}
From 2002 to 2004, three case studies concerning garbage gatherer's organizations, legally called cooperatives, were carried out in the city of Rio de Janeiro, Brazil. Based on the collected data, this article suggests the semantic of garbage (negative and positive) as an important aspect to be considered by the authorities when implementing public policies in this area. The negative semantic seems to be associated with hygienic aspects, what is considered an obstacle to these professionals. At the same time, the positive semantic does not improve their working conditions. This article discusses the possibility of organizing the gatherers in cooperatives as a challenge to the government, which needs to find a better way to interaction with this specific segment in order to understand aspects such as the complexity of their organizations (informal institutions) and the relevance of the semantic of garbage in their economic and social lives.
\end{abstract}

Keywords: semantic of garbage, garbage gatherers, cooperative, recycling, public policy.

1 Doutora pela Escola Brasileira de Administração Pública e de Empresas da Fundação Getulio Vargas-Ebape/FGV. Professora adjunta da Universidade do Grande Rio-Unigranrio. Endereço: Rua da Lapa, 86, $9^{\circ}$ andar, Centro - Rio de Janeiro/RJ - Brasil - CEP: 20021-180. E-mail: scarlet.carmo@ig.com.br. 


\section{Introdução}

Estudos sobre a promoção do desenvolvimento tendem a enfatizar a importância das instituições; ou seja, de estruturas sociais formais ou informais capazes de influenciar o comportamento de agentes econômicos, sociais e políticos (NORTH, 1990). North (1990) define instituições como as restrições formais ou informais ao comportamento humano criadas pelo próprio homem. Elas seriam as regras do jogo que estruturam uma sociedade. O termo desenvolvimento pode ser visto como os objetivos ou metas para os quais sociedades ou países colocam seus esforços. Ele envolveria várias relações causais (INGHAM, 1993).

Adelman e Morris (1967, apud INGHAM, 1993), apesar de não acreditarem na existência de uma receita universal de desenvolvimento, creem que o Estado tem um papel importante na sua promoção e na difusão dos seus resultados para a sociedade por meio de instituições sólidas. A construção de instituições sólidas, então, apresenta-se como a via pela qual as problemáticas inerentes ao desenvolvimento poderiam ser trabalhadas.

Além das instituições, há uma crença de que as questões estruturais são também importantes para a promoção do desenvolvimento (CHENERY, 1974, apud IGHAM, 1993). Muitos economistas tendem a aceitar que tais mudanças estruturais - como a industrialização, a urbanização e a implantação de tecnologias na produção de bens-podem ser um elemento-chave desse processo. Entretanto, tais mudanças podem provocar resistências, na medida em que representam prejuízos para alguns segmentos sociais. Apesar dessas resistências, contudo, elas não necessariamente seriam um impeditivo para uma interação entre o moderno e o tradicional—pelo menos, no caso dos catadores-e o crescente investimento em tecnologias voltadas para o reaproveitamento por parte de diferentes segmentos sociais e o poder público, inclusive. Tomando aqui o moderno como as estratégias que têm sido pensadas pelo Estado para valorizar setores da sociedade, de forma que o desenvolvimento possa neles progredir, este artigo pretende tratar da experiência da prefeitura do Rio de Janeiro no sentido de estimular o trabalho dos catadores de lixo de rua.

Os esforços do poder público em apoiar o trabalho dos catadores teria se originado das discussões travadas na Eco-92, a Conferência das Nações Unidas para o Meio Ambiente e o Desenvolvimento. Realizada no Rio de Janeiro em junho de 1992, a conferência teve como objetivo, entre outros, discutir propostas que conciliassem o desenvolvimento socieconômico com a conservação e proteção ambiental.

Os catadores, contudo, teriam ganho destaque nessas discussões pelo viés social da geração de renda a partir dos resíduos e não, necessariamente, pelos aspectos ambientais que as permeiam. Eigenheer et al. (2005) ilustram bem isso quando comentam que os estudos até então realizados sobre os catadores acenavam para um contexto em que a questão do aproveitamento aproxima-se mais de uma problemática de ordem social e econômica do que ambiental e de escassez de recursos. De acordo com Birkbeck (1979), nos países em desenvolvimento, existiria um mercado de reciclados bem desenvolvido, muito em função da disponibilidade de mão-de-obra barata, disposta a se sujeitar a condições, muitas vezes, difíceis de trabalho. Nesses países a reciclagem seria atrativa em termos econômicos para muitas pessoas (valorização social do lixo). Por outro lado, nos países desenvolvidos a problemática do lixo urbano seria alvo de estudos que contemplam a conscientização ambiental e a tecnologia de reaproveitamento em usinas (BERTHIER, 2003), e a participação da sociedade se daria pela criação de mecanismos institucionais (como as multas) que a induziriam a participar.

No Rio de Janeiro-assim como ocorreu no caso dos garis e em relação ao esforço pela valorização dessa categoria profissional-, a partir da década de 1990, o poder público procurou dar apoio aos catadores de rua, com a formação de cooperativas. Após o estudo de três cooperativas de catadores que surgiram a partir dessa iniciativa, foi possível constatar que esse apoio, entretanto, caminhou lado a lado com a modernização dos processos de coleta, sem que isso tenha significado uma melhoria nas condições sociais e de trabalho.

Mediante estudos foi possível constatar que o acesso dos catadores aos produtores e doadores de resíduos em dois dos três estudos realizados (casos 1 e 3 ) tem se tornado cada vez mais difícil. Foi constatado também, por meio das entrevistas que, diante dos novos segmentos dedicados ao comércio de resíduos-mais articulados 
social, economica e politicamente do que eles—é muito difícil melhorar as condições de trabalho dos catadores sem alguma forma de apoio externo.

Parto do princípio de que o papel do Estado (ou do que ele pôde propor através de suas instituições de auxílio) e a questão da cultura subjacente ao universo dos catadores são o foco deste artigo que mereçam atenção especial, para que se possa pensar uma melhora nas suas condições econômicas e sociais. Por cultura, entendo não apenas os costumes e valores compartilhados, mas também a ideia de mundo ou os significados que englobam as práticas sociais de um determinado grupo e que redundam numa jornada incessante de produção de novos significados. Estes não só moldam as relações sociais como são por elas configurados (ALVAREZ; DAGNINO; ESCOBAR, 2000).

O objetivo principal deste artigo, então, é o de apontar quais as implicações que a mudança de significados (semântica) do lixo tem trazido para o trabalho dos catadores, considerando-se a importância da catação para gerar emprego e renda para pessoas com dificuldade de inserção no mercado de trabalho formal.

Os objetivos intermediários seriam procurar entender de que forma a semântica negativa e positiva do lixo influencia o trabalho dos catadores. Investigar qual o papel do poder público nesse empreendimento ao estimular a formação de cooperativas, como ele atua e como é a receptividade dessa atuação pelos catadores, considerando-se a cultura em que esses atores estão imersos. Embora a mudança do significado do lixo seja algo favorável, e necessário, diante de problemas relativos não só à escassez de recursos naturais (ou de matéria bruta), como dos impactos negativos dos resíduos, ela não tem surtido efeitos benéficos no âmbito social, de acordo com o declarado por alguns catadores.

Se o significado do lixo se modifica, mas as condições de trabalho do catador não se alteram, não deve ser na semântica negativa do lixo e no consequente estigma, apenas, que residem os problemas desses trabalhadores, mas na positividade atribuída ao resíduo. Esse fenômeno é um processo necessário-diante da ameaça ambiental que o lixo representa—e irreversível—conforme o potencial de reaproveitamento e a consequente "commoditização" do lixo. Mas em que condições ele deve ocorrer, de modo a garantir a subsistência do catador? Este artigo procura apontar as implicações da semântica do lixo para os catadores, tentando compreender as condições que permeiam a relação desses atores com a instituição (cooperativas idealizadas pelo poder público) encarregada de promover neles o desenvolvimento, a fim de que atendam (ou se adaptem) às resultantes da disseminação da reciclagem.

\section{Metodologia}

Embora haja diferentes contextos de catação nessa cidade, foram privilegiados aqui três casos de organização de catadores em áreas de lixo rico—-logo, marcadas por elevada competitividade—, mas em que as condições de trabalho são bem diferentes, conforme o modo como se encontram estruturadas. Essas cooperativas seriam as seguintes:

- caso 1: catadores cooperados de uma cooperativa da zona Sul;

- caso 2: classificadores de resíduos cooperados de uma CSR—Central de Separação de Reciclados;

- caso 3: catadores associados de uma cooperativa do Centro da cidade.

Os estudos de caso foram realizados no período de 2002 a 2004. A coleta dos dados ocorreu em uma organização por vez, nos bairros de Copacabana e Botafogo (na zona Sul) e Castelo (no Centro). O período de permanência variou de dois meses (junho a agosto de 2002), no caso 1, a seis meses (abril a outubro), no caso 2 , enquanto no caso 3 foi de julho a dezembro de 2004. As observações foram feitas de três a quatro vezes por semana (caso 1) e de duas a três vezes por semana (casos 2 e 3 ).

A coleta dos dados, inicialmente, foi feita mediante observação direta, quando o observador permaneceu engajado na vida do grupo como um espectador interativo (VERGARA, 2005). Concomitantemente a essas observações, entrevistas abertas e semiestruturadas se deram na medida em que houve maior imersão e 
interação do observador no campo. Essas entrevistas procuram levantar dados inerentes à especificidade de cada um dos grupos observados, de acordo com suas estruturas internas, a relação com o poder público e com os demais atores envolvidos na catação como: atravessadores, coordenadores e geradores.

No caso 1, foram realizadas quatro entrevistas abertas, com três catadores e um administrador, e 17 semiestruturadas, com catadores. No caso 2, foram 11 entrevistas abertas, com cinco classificadores, dois pequenos compradores, três coordenadores de projetos e um administrador, e 21 semiestruturadas, com classificadores. No caso 3, efetivaram-se três entrevistas abertas, com um administrador e dois representantes de uma ONG de suporte, e 11 entrevistas semiestruturadas, com catadores. Foram realizadas entrevistas (abertas) também com um gestor público municipal e dois auxiliares seus.

Os comportamentos em análise neste estudo estão relacionados à interação e à cooperação no trato de questões de natureza econômica e social, buscando identificar canais de auxílio entre catadores e demais segmentos do comércio de recicláveis. A teoria que embasa o estudo dos catadores é a proposta por Geertz (1989) na qual, a partir da observação e da articulação dos comportamentos em um dado contexto, procede-se a uma interpretação que seja uma descrição densa dos significados partilhados pelos atores que interagem na situação estudada. Dessa forma, procurou-se estabelecer uma interseção entre a cultura predominante entre os catadores e a instituição pública que vem trabalhando para auxiliá-los.

\section{Resultados}

\section{A cadeia da reciclagem e o perfil dos catadores}

O processo que se verifica desde a coleta até a destinação final dos resíduos é bastante complexo e envolve diversos segmentos: catador (coleta e venda), cooperativa e/ou sucateiro (compra, triagem e acúmulo), atravessador (compra e acúmulo) e indústria (compra, processamento e retorno ao ciclo de produção). Esses segmentos variam muito em número e características, conforme o tipo de material e a região onde ocorre a coleta, a comercialização e a industrialização. Isso dificulta a descrição/delimitação dos segmentos da cadeia, pois a mercadoria pode passar por diversos desses segmentos (pequenos e médios), antes de chegar ao seu destino final.

A cada etapa, ou segmento, desde a coleta até o beneficiamento, é agregado valor em função do tratamentoseparação por tipo, prensagem e limpeza - e do volume acumulado. Calderoni (1998) nomeia isso de círculo perverso, porque o preço do material vendido pelo catador é bem menor do que o obtido pelos compradores. $\mathrm{O}$ catador não consegue adquirir escala porque não tem condições de acumular. Segundo Medina (1998, 2000), isso ocorre, exatamente, pela sua localização no elo mais frágil da cadeia, porque não possui espaços, nem estrutura para reduzir (compactar/enfardar) o montante obtido antes da venda. Para muitos autores, o modo como a cadeia se estrutura explica o rendimento pífio dos catadores (GONÇALVES, 2003; MEDINA, 1998) e o fato destes serem considerados invisíveis dentro do sistema, já que não conseguem agregar valor ao produto.

No Rio de Janeiro, a maioria dos catadores de recicláveis, aparentemente, tende a se estruturar de três modos distintos: i) como autônomos sem vínculo com organizações; ii) aderindo a organizações (cooperativas ou sucateiros); e iii) os encarregados de classificar o produto e de fazer a separação e o acondicionamento, os quais também estão ligados a alguma forma de organização, embora sem envolvimento com a coleta. Este artigo se ateve ao estudo de três grupos cujas características melhor se enquadram aos modos ii e iii.

Os catadores observados são desde pessoas jovens a idosas. Os jovens, em geral, são filhos de migrantes, possuem baixa escolaridade e pouca experiência em outras atividades profissionais. Os idosos, normalmente, são migrantes e, muitas vezes, analfabetos, cuja atividade anterior era na agricultura, como auxiliares de obra ou como faxineiros.

Os catadores desempenham uma atividade que apresenta barreiras mínimas para a inserção de novos trabalhadores, sendo considerada por muitos deles como alternativa à ausência de trabalho formal. Esses dois 
aspectos reforçam a ideia de que qualquer pessoa sem emprego pode desempenhá-lo. Essa ideia parece justificar a alta rotatividade deles em duas das três cooperativas observadas e explicar a ausência de sentimento de filiação (ou pertença) e de identificação com o trabalho (casos 1 e 2). É o desejo de autonomia e de controle sobre a tarefa que desempenham (trabalhar por conta própria e ausência de patrão) que explicaria o fato de alguns optarem por uma atividade que não exige filiação ou vínculo. Muitas vezes, os catadores apresentam costumes e valores diferentes daqueles preconizados como os necessários em um contexto de mercado de trabalho habitual, como assiduidade e competitividade. O trabalho fora de horários e rotinas determinados e a ausência de patrão representam uma flexibilidade que os trabalhadores habituais nem sempre dispõem (ADAMETES, 1998; PORTILHO, 1997).

Além disso, muitos catadores desconfiam dos órgãos oficiais (poder público) por causa das experiências negativas que tiveram no passado. De acordo com os catadores do Centro da cidade (caso 3), antes da década de 1990, as políticas do poder público eram de repressão às suas atividades, o que teria contribuído para que resistissem à política recente. Isso permite compreender o motivo do aparente embate entre os catadores e as instituições (públicas) que vêm em seu auxílio.

\section{A política de apoio aos catadores no Rio de Janeiro}

Com o intuito de melhorar as condições de trabalho e renda dos catadores, no ano de 1993, a Comlurb apoiou o programa de Cooperativas de Catadores e Carroceiros da Cidade do Rio de Janeiro. Esse programa representou a inclusão da problemática social dos catadores nos projetos voltados para a destinação final dos resíduos. Ele foi gerenciado pela Pontifícia Universidade Católica (PUC-Rio) em espaços doados pela Comlurb com instalações e infraestrutura básica para serem administrados por lideranças eleitas pelos catadores (BRITO, 2001). A adesão dos catadores a esse programa exigia uma ruptura com aqueles costumes e valores tradicionais, na medida em que a assiduidade e a rotina passaram a ser necessários para o bom funcionamento do projeto. Com esses espaços, os catadores de rua teriam condições de acumular o material recolhido antes de negociá-lo.

Formada por aproximadamente 5.544.837 habitantes e uma área de 116.848,48ha, esta cidade divide-se em regiões (ou áreas de planejamento): zona Sul, Centro, zona Norte e zona Oeste. A zona Sul é caracterizada como uma região de moradia e abarca população com maior poder aquisitivo, logo produz um "lixo rico". O Centro é o polo comercial e financeiro da cidade, tem poucos habitantes, mas produz um "lixo muito rico", totalmente separado de matéria orgânica. A zona Oeste e a zona Norte são regiões com um número elevado de habitantes, mas de menor poder aquisitivo, que produz um "lixo pobre", misturado à matéria orgânica. Essa distribuição geográfica faz com que a catação de resíduos nas ruas se concentre na zona Sul e no Centro, para onde pessoas de bairros longínquos, quando não de outras cidades, acorrem diariamente.

O lixo nela gerado é depositado em um aterro que se encontra no seu limite. Como forma de solucionar o problema dessa vazão, em 1977, ocorreu a primeira intervenção do poder público no âmbito da reciclagem, ao inaugurar a Usina de Irajá. Essa intervenção marca o ponto de partida na busca de soluções para a questão da vazão dos resíduos sólidos. É a partir das discussões produzidas na Eco-92 sobre a questão ambiental, contudo, que o poder público procurou resolver esse problema da vazão, incluindo também a problemática dos catadores de lixo. Outras iniciativas como essa ocorreram pelo país na mesma época. Entre elas está a atuação do poder público de Belo Horizonte, em decorrência do empenho da Asmare (Associação de Catadores de Papel, Papelão e Material Reaproveitável), que reivindicou uma conduta diferente em relação aos catadores, que lá também eram marginalizados.

À certa altura, contudo, o poder público municipal do Rio de Janeiro constatou que o programa de cooperativas de 1993 não atingira o propósito de superar a importância dos pequenos atravessadores no processo de negociação dos recicláveis. Essa constatação levou a Comlurb a se afastar da coordenação desse projeto, já que quem passou a usufruir da estrutura oferecida não teriam sido mais os catadores, conforme o esperado, mas os seus líderes (ou pequenos atravessadores). Como consequência, as cooperativas formadas não se tornaram organizações viáveis economicamente e autossustentáveis, conforme o desejado. 
O poder público se afastou desse projeto, lançando na década seguinte uma nova proposta. No ano de 2001 foi reativada uma usina de separação fechada em 1994 e lançados os Eco-pontos-depositários de material proveniente de residências. Em 2002, foi implantada a coleta seletiva em escolas e, no ano seguinte, inaugurada a primeira CSR (Central de Separação de Reciclados), uma cooperativa de classificadores de resíduos proveniente da coleta seletiva urbana, que foi expandida para mais quatro núcleos.

Diferente do programa de 1993, todos os núcleos da CSR são administrados por cooperativas gestoras, escolhidas por licitação pública e operadas por profissionais (classificadores de resíduos) contratados diretamente pela Comlurb. Esses profissionais, de acordo com a região, não seriam catadores tradicionais, mas pessoas desempregadas ou jovens se inserindo no mercado de trabalho pela primeira vez.

Concomitantemente a essas iniciativas, no entanto, outros segmentos da sociedade começaram a desenvolver seus próprios projetos ligados à coleta de recicláveis, seja por interesse financeiro ou altruísmo. Assim, além das firmas especializadas em coleta de resíduos de grandes prédios comerciais, as empresas (firmas, escritórios etc.) passaram a delegar aos seus funcionários a tarefa de separar e vender o resíduo delas oriundo. Conforme a fonte geradora desse material, o dinheiro obtido com a venda poderia ser revertido para a manutenção e a compra de produtos de limpeza.

Um exemplo de iniciativa altruísta partiu de uma ONG fundada em 2003, dedicada à coleta de material de bancos e escritórios na região do Centro da cidade. Sua estratégia de trabalho e sua finalidade teriam se tornado imbatíveis em comparação com o desempenho dos catadores de rua. Por conta do fornecimento periódico de um balanço dos resíduos às empresas geradoras, essa ONG mantinha um vínculo forte com essas empresas geradoras devido à oferta de um serviço difícil de ser oferecido pelos catadores (ARRUDA, 2005). São iniciativas isoladas, como a dessa ONG particularmente, que exemplificam o que aqui é denominado fenômeno de valorização social do lixo (ou semântica positiva do lixo).

Dias (2002) acredita que a atenção dispensada pelo poder público à questão dos catadores foi resultado de um processo de democratização da gestão pública em curso, aliada às discussões relacionadas com a responsabilidade ambiental, ocorridas no âmbito mundial. Exemplo disso, é que, entre 2000 e 2001, o governo federal, através do FNMA (Fundo Nacional do Meio Ambiente), lançou os editais FNMA n ${ }^{\text {os }}$ 06/2000, 05/2001 e 12/2001 para selecionar propostas voltadas para o Programa de Gestão Integrada de Resíduos Sólidos (PGIRS), vinculado ao Ministério do Meio Ambiente. Criado para buscar soluções para os impasses relativos ao meio ambiente em cidades com população entre 20.000 e 100.000 habitantes, o PGIRS previa, entre suas ações, instalar o Fórum Municipal do Lixo e Cidadania (FMLC), mobilizar a sociedade para que acompanhasse e gerisse os resíduos urbanos e apoiar à organização dos catadores como categoria profissional, através da formação de associações ou de cooperativas.

Hoje, os catadores são reconhecidos como categoria pela CBO (Classificação Brasileira de Ocupações), graças a diversas iniciativas - com a participação deles ou em prol deles-, através da realização de fóruns e como resultado de medidas de apoio tomadas tanto pelo poder público das esferas federal, estadual e municipal quanto pela iniciativa privada. O Fórum do Lixo e Cidadania (FELC) teria permitido que catadores provenientes de localidades distintas se reunissem para elaborar discursos sobre sua realidade de trabalho. Criado em 1998, o fórum é um encontro de órgãos governamentais das três esferas, de ONGS e de grupos que atuam em áreas relacionadas ao problema da gestão do lixo urbano e aos desafios da ordem social (GONÇALVES, 2003).

Além desses eventos nacionais há também as mobilizações locais. No caso do Rio de Janeiro, a Rede Independente de Catadores de Materiais Recicláveis (Ricamare), fundada em 2003 a partir da associação de mais de 20 grupos de catadores, organiza eventos a cada dois meses para discutir questões inerentes ao trabalho dos catadores, como políticas públicas e formas de organização e de beneficiamento (GONÇALVES, 2003). Diversos atores sociais atuam como parceiros da Ricamare nesse projeto-como ONGs, associações de moradores, instituições filantrópicas, igrejas e entidades de ensino superior-que procuram envolver os catadores informais nas discussões relativas à categoria. Apenas o estudo de caso 3 envolve integrantes que já 
participaram de alguns desses encontros promovidos pelo fórum. Ao estabelecer comparações entre o discurso desses três grupos, constatou-se que esses encontros ajudam na formação de massa crítica entre os catadores.

No Rio de Janeiro, entretanto, haveria uma dificuldade de organização em grupos de discussões como esse, quando comparados com a articulação que há muito tem mobilizado esses profissionais em Belo Horizonte e em São Paulo (DEL GAUDIO, 2003; DIAS, 2002;). A alta rotatividade pode ser uma pista, pois apenas no caso 3 os catadores manifestam interesse em permanecer na profissão.

Uma coisa é certa: essas iniciativas paralelas, ao mesmo tempo, ajudam a dar visibilidade ao trabalho do catador - consequentemente, contribuindo para amenizar o estigma da profissão - e a modificar o significado do lixo para a sociedade (semântica do lixo). A política de apoio aos catadores do Rio de Janeiro ocorreu concomitantemente a essa mudança na representação assumida pelo lixo. O desafio é fazer com que o catador usufrua desse processo de mudança em curso, em vez de sofrer o impacto que isso possa causar na sua subsistência. A seguir, será abordada a semântica do lixo e como ela se manifesta nos três estudos de caso já mencionados.

\section{As políticas de apoio-estrutura dos três estudos de caso e seus desdobramentos}

A estrutura do trabalho é um pouco distinta em cada um dos grupos observados, devido à localização geográfica deles (bairros residencial, nos casos 1 e 2, ou comercial, no caso 3), às formas de administração, à origem do lixo e ao modo como o catador tende a nele se inserir. Apesar de essa estrutura ser distinta, todos os três grupos recebem apoio do poder público, o qual, além de disponibilizar espaços para armazenagem, coleta os restos não aproveitáveis entre o que é coletado por eles e fornece água e energia elétrica (BRITO, 2001; CARMO et al., 2005). O quadro 1 resume a estrutura de cada uma das cooperativas observadas.

Quadro 1- Estrutura das cooperativas de catadores

\begin{tabular}{|c|c|c|c|}
\hline & Caso 1 & Caso 2 & Caso 3 \\
\hline $\begin{array}{l}\text { Características do } \\
\text { resíduo }\end{array}$ & Rico & $\begin{array}{r}\text { Separado (bom grau } \\
\text { de pureza) }\end{array}$ & Muito rico \\
\hline Origem do resíduo & Comércio e moradia & Moradia & Comércio \\
\hline Gestão & $\begin{array}{r}\text { Ex-dono de caminhão } \\
\text { (pequeno atravessador) }\end{array}$ & Cooperativa gestora & $\begin{array}{r}\text { Ex-catador apoiado } \\
\text { por uma ONG }\end{array}$ \\
\hline Pesagem & Gestor & $\begin{array}{r}\text { Líder entre os } \\
\text { cooperados }\end{array}$ & $\begin{array}{r}\text { Catadores } \\
\text { individualmente }\end{array}$ \\
\hline Logística & Coleta e venda & $\begin{array}{l}\text { Classificação, } \\
\text { acúmulo e venda }\end{array}$ & $\begin{array}{r}\text { Coleta, classificação, } \\
\text { acúmulo e venda }\end{array}$ \\
\hline Ambiente de coleta & Indeterminado & $\begin{array}{r}\text { Inexistente (devido à } \\
\text { coleta seletiva) }\end{array}$ & $\begin{array}{l}\text { Pré-determinado } \\
\text { (donos de ponto) }\end{array}$ \\
\hline Inserção na atividade & $\begin{array}{r}\text { Mediante indicação ou } \\
\text { procura }\end{array}$ & $\begin{array}{r}\text { Mediante indicação } \\
\text { ou procura }\end{array}$ & Vocação herdada \\
\hline Ganhos por produção & Individual & Coletiva & Individual \\
\hline
\end{tabular}

Fonte: elaborado pelo autor

Conforme já colocado, essas cooperativas se localizam em áreas de lixo rico. Essa riqueza deve-se ao padrão de vida e de consumo de seus habitantes, bem como à proximidade de centros comerciais ou de áreas de escritórios. Isso tanto atrai catadores para a região, provenientes de bairros e distritos afastados, como leva a uma elevada competitividade por espaços entre eles.

A gestão das cooperativas, no caso 1, é realizada por um ex-dono de caminhão (ou pequeno atravessador) que delega a um funcionário de sua confiança a tarefa de pesar e pagar a mercadoria. Embora os três casos sejam definidos como cooperativas, os casos 2 e 3 são os que mais se aproximariam dessa definição, pela gestão democrática do negócio, pela participação coletiva nos ganhos (caso 2 apenas) e pelo fato de as decisões serem 
tomadas em grupo. Embora nesses dois últimos casos o gestor tenha sido escolhido pelo poder público (caso 2) ou pela ONG que os apoia (caso 3), as pessoas encarregadas de estabelecerem a ordem entre eles e de controlar a contabilidade e a produção são pessoas nas quais os catadores de certa forma confiam, diferentemente do caso 1 .

O fato de o resíduo ser pesado pelo administrador das cooperativas em geral, segundo Magera (2003), sugere a existência de alguma forma de submissão ou de exploração dos catadores através do controle da balança. $\mathrm{O}$ caso 1 se aproxima dessa sugestão de Magera. Já nos casos 2 e 3 o controle da balança é realizado, respectivamente, por um representante dos catadores e por cada catador individualmente. Porém, é por meio da logística, representada pelas tarefas desempenhadas pelo catador, que vai ser possível identificar o grau de envolvimento e de participação dele na vida da organização a que pertence. No caso 1, a tarefa do catador se restringe a coletar e a vender para o comprador (gestor da cooperativa). No caso 2, ela se resume a classificar, acumular e a vender. No caso 3, eles coletam, classificam, acumulam e vendem; logo, participam de todo o processo pelo qual deveriam passar, conforme o proposto pelo poder público em termos de agregação de valor, conforme a qualidade e a quantidade (escala) alcançados.

Quanto ao ambiente de coleta, nos três grupos ele é bem distinto, pois de acordo com o local em que está localizada a cooperativa, os catadores teriam acesso a pontos de coleta pré-determinados (caso 3) ou não (caso 1). Essa afirmação, contudo, não se aplica ao caso 2 porque os trabalhadores não recolhem material nas ruas, eles recebem-no direto da coleta seletiva urbana.

Com exceção do caso 3, a inserção no trabalho deu-se pela indicação de colegas ou de parentes também catadores, que tinham apresentado a muitos deles as oportunidades que a coleta de resíduo pode representar para a sua subsistência. O caso 3 seria exceção porque a maioria daqueles trabalhadores teria nascido e crescido junto a catadores e, naturalmente, foram se inserindo nessa atividade. Muitos deles seriam, inclusive, filhos de catadores que acabaram herdando o ponto dos pais, daí a ideia de vocação herdada colocada anteriormente.

Por fim, é interessante comentar sobre o recebimento do valor negociado, que ocorre de acordo com a produção de cada um. Esse recebimento ocorre de modo diferente nos três casos. Enquanto nos casos 1 e 3 é feito individualmente, no caso 2 é feito conforme a produção coletiva. Essa distribuição coletiva geraria discordâncias entre eles, na crença de que nem todos merecem ganhar valor idêntico, já que não trabalhariam de modo idêntico também. Esse tipo de discussão inexiste entre os trabalhadores dos outros dois casos, provavelmente, pelo trabalho de forma individualizada e sem divisão de tarefas. Este artigo acredita que esse fato é um dado interessante a se considerar, uma vez que em diversos momentos foram constatados conflitos entre o grupo, em função dos mal-entendidos que esse modo de distribuição da renda gera.

\section{Discussão}

Os catadores podem ser definidos, entre outros aspectos, como uma categoria profissional que sofre o impacto da semântica negativa do lixo e que por isso seria alvo de estigmas. O estigma se deve à repugnância ao lixo, visto apenas pelas suas características negativas (semântica negativa) também direcionadas às pessoas que o manuseiam profissionalmente. Por semântica negativa do lixo entende-se o conjunto de conotações ruins atribuídas a esse objeto na cultura ocidental. Essas conotações advêm das características dos resíduos inorgânicos (o odor, a aparência e a decomposição), que interferem no valor da mercadoria seca, apropriada para o reaproveitamento. A semântica do lixo, devido ao estigma, explicaria não só a falta de reconhecimento social do trabalho dos catadores, por parte da sociedade (geradora de resíduo aproveitável), bem como as dificuldades de articulação deles no mercado de recicláveis, em franca expansão. Isto é, ela justificaria a dificuldade de formação de redes de cooperação e auxílio mútuos entre catadores, compradores, poder público e os próprios geradores.

O nojo do lixo "contaminaria" o trabalho dos catadores, muitas vezes, definido como tarefa típica de pessoas marginais e sem qualificação profissional (MEDINA, 2000, 2007). Eles próprios se representariam como pessoas estigmatizadas (PORTILHO, 1997). Esse nojo deve-se a uma ideia de contaminação (ASHFORTH; 
KREINER, 1999; DOUGLAS, 1966) pelo simbolismo e, consequente, associação com lixo, morte, doença, caos e desordem (EIGENHEER, 2003; RODRIGUES, 1992), que também diriam respeito a esses trabalhadores. Há uma tendência, segundo eles, da sociedade confundi-los com os objetos que coletam, com mendigos ou com ladrões.

Apesar de campanhas de reaproveitamento de resíduos virem surtindo efeito positivo em relação ao modo como a sociedade passa a representar o lixo, parece que elas não mudam a representação social do trabalho dos catadores. Dessa forma, é possível admitir que, atualmente, os catadores, além de terem de suportar o peso do estigma, enfrentam ainda dois desafios: 1) a modernização dos processos de coleta e 2) a valorização social dos resíduos.

A modernização do sistema de coleta ocorre a partir do desenvolvimento de tecnologias que facilitam o retorno do material ao ciclo produtivo. Esse fato é perceptível pela iniciativa do poder público de implantar a coleta seletiva. Já o segundo desafio é constatado pela atribuição de valor ao reciclável e pela capacidade de discernimento entre o material aproveitável e o não aproveitável—discriminação entre lixo orgânico e inorgânico-, resultantes da educação ambiental e de campanhas de organismos ligados ao meio ambiente, que teriam contribuído para uma mudança em relação ao significado do lixo pela sociedade.

Não obstante essa capacidade de discriminação da sociedade, o significante lixo sempre terá uma conotação negativa. Entretanto, o que interessa aqui é esclarecer sobre a tomada de consciência que permite verificar que, em meio a tudo aquilo que se classifica como "lixo", há objetos aptos a serem associados a algo útil. É a capacidade de circulação e retorno de alguns objetos ao ciclo produtivo que permite esse tipo de associação. No entanto, é a tomada de consciência da sociedade, em geral, quanto a essa noção de utilidade que permite pensar em uma semântica positiva do lixo (ressemantização), uma vez que a capacidade de circulação e retorno não é em si algo recente, já que os catadores há muito trabalhariam com isso. É o interesse dos geradores (de resíduos recicláveis) que leva à ideia de uma valorização social do lixo. Com isso, consequentemente, o comércio de recicláveis obtidos na fonte não é mais uma atividade exclusiva de catadores.

Tanto aquela modernização dos processos de coleta quanto a valorização social dos resíduos interferiria nos ganhos dos catadores. A valorização social do resíduo é perceptível tanto pelo depoimento dos catadores entrevistados, como pelo fato do resíduo passar a ser nomeado como reciclável pela sociedade e mencionado como uma commodity pela mídia (RODRIGUES, 2005). Isso significaria que a partir de um determinado momento os catadores teriam passado a competir com empresas, com organizações não-governamentais (ONGs) dedicadas à reciclagem e com os próprios geradores interessados em vender seus restos (aproveitáveis). Esse fato teria coincidido com o estabelecimento de discussões sobre a reestruturação e o apoio a esse seguimento profissional por parte do poder público, conforme o projeto de apoio do Rio de Janeiro.

A situação de estigma vivida pelos catadores é muito diferente do contexto de trabalho dos lixeiros (garis). Se até bem pouco tempo atrás estes desempenhavam uma atividade alvo de estigma (PORTILHO, 1997), hoje em dia ela tem sido disputada por número excessivo de candidatos quando de concursos públicos. Por exemplo, o concurso para garis da Comlurb (Companhia Municipal de Limpeza Urbana) em 2003 teve mais de 120.000 inscritos, muitos deles com nível superior. Essa mudança na representação do trabalho dos lixeiros e o interesse social pelo desempenho dessa tarefa é fruto de intenso investimento do poder público para a melhoria da imagem desses trabalhadores perante a sociedade. Também é resultado da escassez de oportunidades de trabalho com estabilidade no Brasil, fazendo com que ser gari leve a pessoa a fazer parte de uma minoria que tem carteira assinada, salário razoável e garantia de trabalho em face do desemprego estrutural e do consequente aumento da informalidade. 
Em estudo sobre os catadores de usina de Vitória, no Espírito Santo, Nogueira (1996) mostra que eles teriam passado a se sentirem integrados à categoria de trabalhador depois que largaram o lixão, devido ao que a mudança nas condições de trabalho teria representado em suas identidades sociais. Como se tivessem deixado de desempenhar uma tarefa degradante e passado para a classe de trabalhadores no momento em que as condições para o desempenho de suas tarefas melhoraram.

A semântica negativa do lixo parece colocar o catador em uma situação de desvantagem quanto à sua cidadania, pois o estigma contribuiria para mantê-lo excluído socialmente, inclusive, dos assuntos relativos ao trabalho e sua organização. O lixo (ou resíduo), por ser considerado aquilo que perdeu a utilidade ou valorpor isso, descartado pela sociedade—, está impregnado de conotações pejorativas (EIGENHEER, 2003; PORTILHO, 1997; RODRIGUES, 1992, 1995). Dessa forma, a tarefa dos catadores seria classificada como degradante devido à proximidade com esse objeto. Isso dificultaria a organização desses trabalhadores de forma autônoma, pelo peso do estigma, e alimentaria um círculo em que, quanto mais próximos de serem marginalizados-como quando associados a mendigos—, menos organizados eles são e menor é a possibilidade de reconhecimento social e apoio. A semântica negativa cria instituições (no sentido de North, 1990) que dificultam a organização dos catadores em cooperativas fortes, para terem uma melhor posição na cadeia dos resíduos, e com isso mudar sua posição social e econômica. Essas instituições dificultam tanto a relação entre os mesmos colegas catadores quanto entre eles e a sociedade e o poder público.

A influência da semântica do lixo no trabalho dos catadores não é diferente nos três grupos. Nessas organizações, o lixo é valor para os catadores, mas também é causa de estigma pelo que isso teria passado a significar para os outros (as demais pessoas da sociedade com quem interagem). Mesmo que as demais pessoas da sociedade passem a ver o reciclável como algo de valor-“"Até artista e empresário estão se interessando pelo lixo agora", conforme uma catadora do caso 3, em menção ao impacto daquela ONG fundada em 2003 no Centro da cidade-isso não ajuda a mudar a imagem social desses trabalhadores. Ajuda, sim, a que a tarefa fique mais competitiva. Já que, segundo os catadores ouvidos, tanto doadores (geradores) como compradores continuariam a achar um favor comprar o material coletado por eles, como outrora.

Se fosse possível estabelecer uma síntese do que os atores dos três casos, separadamente, pensam a respeito do próprio trabalho, ela poderia ser assim descrita: vergonha e necessidade de justificar a opção por essa tarefa, passando pela apatia, até o orgulho pela profissão. Vergonha, apatia e orgulho são termos que dão a ideia de uma gradação entre os três casos e que, apesar do estigma do trabalho, não os impede de reconhecer as vantagens de ser catador, assim como ajuda a perceber a influência que o apoio do poder público pode ter tido na construção de uma identidade profissional. Essa influência seria perceptível ao se procurar estabelecer uma relação entre os casos e se constatar que lá onde essa atuação parece que era menos presente—ou seja, no estudo de caso 1-, os catadores praticamente não participavam das decisões internas da "cooperativa”. É nesse mesmo caso que, em função do estigma, seria maior a tendência deles sentirem vergonha de assumir seu trabalho perante familiares e amigos.

Apesar dessa semântica negativa do lixo ainda representar um peso no desempenho dessa atividade, os três estudos de caso revelariam estágios distintos do empreendimento feito pelo poder público para melhorar as condições sociais e de trabalho dos catadores. $\mathrm{O}$ caso 1 seria mais rudimentar em termos de uma organização coletiva, enquanto os casos 2 e 3 estariam num patamar mais avançado, já que, de vergonha, foi possível pensar em apatia e, depois, em orgulho em relação ao trabalho.

Até aí, tudo bem, se os problemas relativos à identidade e autoestima pela via trabalho não tivessem sido substituídos por falas mais centradas em questões relativas à economia da reciclagem, à exploração e à nostalgia de uma época em que coletar era algo menos competitivo. A apatia do caso 2-que também pode ser identificado como o daquele grupo em que a ausência de transparência nas transações é acentuada-leva os catadores a se sentirem explorados pelos gestores, ao passo que a nostalgia seria o sentimento comum no terceiro estudo de caso. 
Aos poucos, aquilo que poderia ser inerente a um trabalho estigmatizado, ganha ares de trabalho explorado, conforme a questão do comércio adquire proeminência. Quanto mais organizados, mais forte torna-se esse discurso.

A relação dos catadores com o trabalho oscila entre a ideia de tarefa temporária-enquanto não aparece uma oportunidade com carteira assinada (casos 1 e 2) - e a de uma atividade interessante-por possibilitar rendimentos maiores do que num emprego formal.

A catação também é vista como uma atividade com horário mais flexível (casos 1 e 3), mesmo sob o peso do estigma. "Eu voltei para esse trabalho, apesar de ser um trabalho meio assim [...] que trabalha com o lixo". Esse comentário partiu de um catador do estudo de caso 1 e ilustra certa divisão interna entre aqueles que optaram por catar em função do rendimento ser muitas vezes maior do que no trabalho formal. Nesse sentido, os catadores desconheceriam a lógica de mercado e suas oscilações de preço; tendendo a sentir, apenas, as suas consequências, como, por exemplo, o efeito da sazonalidade no valor pago. Essa sazonalidade leva a uma oscilação no preço porque o descarte é maior na rua nos períodos em que é menor a demanda industrial por recicláveis. Como não têm condições de armazenar o produto como fazem os intermediários, os catadores o acabam vendendo pelo preço do momento.

Essa alteração de preço costuma ser entendida como má-fé dos compradores e do poder público. Um exemplo disso é a afirmação de um deles de que o dinheiro obtido na CSR "vai para o bolso da Comlurb". Essa afirmação ilustra também a incompreensão sobre a formalização e necessidade de pagamento de tributos e o desconhecimento sobre o empenho necessário para driblar os riscos de um mercado oscilante. Isso, contudo, não significa que não haja oportunismo por parte de alguns integrantes dessa instituição, como também por parte dos compradores.

A dificuldade que os trabalhadores têm de compreender a lógica do comércio de resíduos, todavia, parece, no caso 2 , ter origem na falta de transparência nos negócios. Os trabalhadores deste estudo manifestaram um permanente estado de desconfiança em relação aos gestores da cooperativa e ao poder público. O poder público é alvo de comentários porque participa diretamente da vida dessa organização, já que enquanto a cooperativa gestora se encarrega da contabilidade e cálculo dos salários, aquele fornece o material para separação e recruta o pessoal para trabalhar na classificação do material.

Nos outros dois casos, apesar da lógica do comércio lhes ser incompreensível, o modo como negociam o material impede que se possa falar em falta de transparência na organização. As pessoas alvo de críticas e de desconfiança entre eles seriam aquelas com quem lidam no dia-a-dia. No caso 1, a desconfiança generalizada recairia sobre o administrador do local. Esse administrador compraria o material deles e o repassaria depois para um atravessador de porte médio, de modo que ele seria o único a se beneficiar das vantagens da escala em um espaço que teria sido cedido pelo poder público para que catadores de rua pudessem usufruir das vantagens desse acúmulo. No caso 3, as críticas ou desconfianças são canalizadas somente para o poder público. Eles consideram que o poder público seria omisso diante da valorização social do lixo por não apoiar o pessoal autônomo de rua, que ainda não teria, como esses catadores, espaços de trabalho. Um catador explica: "Antes, era tudo doado pra gente!", sugerindo que as coisas tinham mudado e que agora estava cada vez mais difícil subsistir do comércio de resíduos recicláveis.

O apoio que os catadores teriam recebido do poder público parece que não ajudou muito, nem a superar os desafios impostos pelo mercado, nem a estabelecer vínculos fortes com o trabalho e com os demais segmentos da cadeia de reciclagem (compradores da mercadoria de médio porte), apesar de contribuir para a atribuição de uma semântica positiva ao lixo.

Segundo Velloso (2005), o modo como o Estado intervém impede que as experiências dos catadores sejam assimiladas pelas propostas do poder público. Isso talvez ajude a explicar a impressão de apatia e o baixo nível de confiança entre eles mesmos e deles em relação aos gestores das organizações em que atuam. Os três estudos de caso confirmam, cada um ao seu modo, essa afirmação de Velloso, o que parece mais nítido no caso 2. Se por um lado o poder público teve um papel importante no processo de estruturação de algumas 
organizações de catadores da cidade, por outro não foi capaz de estimular lideranças capazes de transmitir-lhes a lógica subjacente ao mercado de recicláveis (pautado pela economia de escala, pelo descarte sazonal e pelo mercado competitivo).

Assim, a dependência de pessoas mais familiarizadas com essa lógica nem sempre é uma questão de escolha pessoal, mas de necessidade. As iniciativas do poder público, segundo a ótica dos administradores de projetos da Comlurb, não surtiram os resultados esperados, devido aos hábitos dos catadores, avessos à assiduidade, à rotina, ao comprometimento e à obediência. Eles retratam os catadores como pessoas que não são comprometidas e que se recusam a pagar os tributos que um empreendimento dessa natureza exige. Considerando-se o aspecto gerencial, a alta rotatividade dos catadores interfere na aquisição de expertise e leva a uma necessidade de treinar constantemente novos trabalhadores, conforme as lições tiradas do caso 2, mais especificamente. Isso impede o desenvolvimento de uma organização com uma atuação mais participativa, pautada por regras e normas explícitas e comuns a todos, tal como propusera o poder público, bem como impede que o grupo assimile a lógica desse mercado.

Os catadores, por sua vez, declaram que essas iniciativas do poder público não lhes teria trazido benefício algum. Suas condições de subsistência, pelo contrário, teriam piorado, já que muitos ganhariam mais na informalidade das ruas (apesar dos perigos e piores condições de trabalho) do que no interior de instalações onde passariam a ter de pagar alguns tributos. Por fim, retratam o poder público como uma instituição cujos modelos de gestão não levaram em consideração as suas reais demandas. A experiência da organização de catadores de Belo Horizonte, em Minas Gerais, (DIAS, 2002) e o estudo de caso 3 mostram que, mediante uma parceria entre catadores e setores mais articulados da sociedade (ONGs), é possível atender às suas demandas. Uma organização capaz de dar-lhes possibilidades de acesso a processos de comercialização mais transparentes e compreensíveis é o que eles desejam, segundo as análises dos três estudos de caso, além de acesso ao resíduo tal como obtinham outrora (antes deste se tornar socialmente valorizado).

Se os catadores apresentam uma estrutura de trabalho à margem de uma lógica habitual, a interação com segmentos sociais mais articulados, representados por instituições de auxílio como o poder público, teve como objetivo inicial procurar adaptá-lo a essa lógica. No entanto, essa proposta de que eles deveriam procurar atender às exigências do mercado de reciclados (qualidade, competitividade, escala) gerou conflitos entre a proposta de um (poder público) e as expectativas de outros (catadores). Esses conflitos serviram mais para que um sentimento de revolta ou decepção fosse gerado entre ambas as partes do que para a promoção de melhorias sociais e ambientais. Como consequência, esses conflitos passaram a interferir na representação que um ator tem do outro: o poder público passa a ser visto pelo catador como um organismo que age contra seus interesses; o catador, por sua vez, é representado pelo poder público como um grupo que não consegue se adaptar a regras.

O poder público é o ator que tenta de alguma forma trabalhar para a inclusão do catador no contexto emergente, de modernização das técnicas de coleta, ao tentar fornecer estrutura e condições de trabalho. Contudo, é difícil para o catador, por enquanto, identificar o lado positivo dessas iniciativas. Até o momento, o impacto da mudança na semântica do lixo para a sociedade é algo negativo, já que aguçou o interesse dela por essa mercadoria, mas não ampliou os rendimentos dos catadores.

Em discussões sobre desenvolvimento econômico, dois elementos têm importância crescente: a questão da cultura e a dos modelos institucionais que organizam o comportamento dos agentes. A cultura não é uma coisa, como bem afirma Geertz (1989), mas um contexto informado e criado a partir de uma perspectiva simbólica de entendimento do mundo. Conforme Spink e Menegon (2000, p.80), a cultura pode ser entendida como "uma espécie de organização cognitiva socialmente compartilhada". Ela seria a concepção de mundo que ajuda a dar conformação às práticas sociais, num processo incansável de produção de significados que configuram a experiência e ajudam a modelar as relações sociais (ALVAREZ; DAGNINO; ESCOBAR, 2000).

A estrutura social, por sua vez, é composta de indivíduos que ocupam posições distintas e cujas relações ou interações entre eles são pautadas por regras e normas de comportamento que se institucionalizam conforme permanentemente praticadas. Durante essas interações, todavia, tanto as instituições como as definições de status conferidas aos indivíduos sofrem mudanças e se reformulam. É mediante as interações que os indivíduos 
definem novas formas de relação ou reformulam aquelas já estabelecidas. Nessas interações, as relações se consolidam e se institucionalizam, e aquelas normas amplamente compartilhadas que contam com um forte apelo social—mas que não são formalizadas, nem tampouco explicitadas pelo padrão vigente—são denominadas instituições informais.

As estratégias de desenvolvimento tendem a focar suas atenções em resultados, sem contribuir muito para a compreensão das microestruturas institucionais das quais elas dependem (EVANS, 1996a, 1996b). Este estudo propõe a hipótese da sinergia ao unificar esforços para ligar a questão das instituições à do desenvolvimento. Em uma economia capitalista, ambos as instituições burocráticas públicas e as comunidades informais devem se complementar, de maneira a levar à melhoria de condições sociais dos indivíduos afetados em um contexto também dominado pelas relações de mercado. A ação resultante da interação entre Estado e organização social deve levar a um resultado que fortaleça a posição das organizações sociais no mercado, já que muitas delas estão no lado mais frágil da cadeia. Esse é o caso das organizações de catadores.

No entanto, para isso é importante que haja uma boa relação entre os representantes do Estado e as organizações sociais. Essas ações do Estado, por sua vez, devem ajudar a cimentar as relações entre os diversos indivíduos dessas organizações sociais. Relações geralmente pautadas pela desconfiança entre esses dois segmentos; muitas vezes, estimulada pelas condições sociais e históricas.

No caso dos catadores, por exemplo, o poder público tende a ser representado por eles do mesmo modo como, habitualmente, retratam seus compradores, os atravessadores; ou seja, como uma instituição que age por interesses próprios (financeiro ou eleitoreiro), daí, sentirem-se usados. Contudo, cabe lembrar que os atravessadores, por exemplo, são um segmento imprescindível no comércio dos reciclados, embora frequentemente representados como vilões por sua ligação com o repasse e com a valoração do produto; logo, com a determinação do preço (BERTHIER, 2003; MAGERA, 2003; MEDINA, 1998, 2000). Sem a atuação deles o reciclável não teria como retornar ao ciclo de produção e nem todos os elos da cadeia funcionariam em condições ideais.

No que tange ao poder público e sua relação com os catadores, é possível afirmar o mesmo-de que, no momento, ele seria imprescindível para a atuação do catador. O problema é quando a aparente falta de articulação dos catadores a demandar uma ação do poder público esbarra na impossibilidade dessa instituição atender às questões deles, levando-os a não aderirem às estruturas de trabalho propostas. É como se, ao ensaiarem um trabalho conjunto, catador e poder público acabassem esbarrando em adversidades causadas pela falta de interação entre o viés institucional, de um lado, e a lógica cultural dos catadores, de outro. Na concepção dos catadores, o Estado não é para todos, como se as práticas estabelecidas e universalmente aceitas - ou seja, as crenças e pressupostos pelos quais os indivíduos se pautam (instituições, tal como se colocam)—não lhes dissessem respeito. Na concepção do poder público, os valores e hábitos dos catadores não condizem com o que se espera do bom empreendimento do negócio por ele proposto.

Segundo Evans (1996), as associações burocráticas, muitas vezes, não são capazes de replicar a eficiência das iniciativas comunitárias. Mesmo uma pessoa com uma trajetória longa de ocupação oficial de uma função numa determinada área particular não pode replicar o conhecimento de lideranças locais. No caso dos catadores, isso fica claro nas suas declarações, quando apontam a necessidade do poder público aprender a escutá-los e atender às suas demandas, a partir daquilo que realmente necessitam e não somente do que este supõe ser o melhor para eles. Se verificarmos o quadro 1, as tarefas a que o catador acede, desde a coleta até a venda, só foram alcançadas por um dos casos (caso 3). No outro (caso 2), em que não coletam, mas vendem, eles pagam tributos, o que torna a atividade pouco interessante (financeiramente) para um catador de rua autônomo. Logo, o problema não é coletar nas ruas; o problema é desconhecer o que seja o comércio. Assim, a questão não está no fato de se trabalhar nas instalações cedidas pelo poder público, mas em se trabalhar nelas de acordo com o que propõe quem as administra. Nesse sentido, o problema não seria a semântica negativa do lixo, mas o fato deles não serem suficientemente competitivos para suportarem o efeito dessa semântica em suas economias sem o apoio externo, que, por sua vez, não lhes atende como esperado. 


\section{Conclusão}

A experiência da prefeitura do Rio de Janeiro no sentido de estimular o trabalho dos catadores mostrou que a semântica positiva do lixo tem exigido uma mudança na forma como esses profissionais se organizam. O poder público e algumas ONGs vêm trabalhando para mudar o complexo modo de organização desses profissionais, que não lhes traz, necessariamente, retorno em termos de rendimentos. Essa mudança ocorreria na forma de um apoio para que os catadores consigam atender diretamente (sem dependerem de terceiros) às exigências do mercado e, assim, sejam fortalecidos na cadeia da reciclagem.

Muitos acreditam que o uso de uniformes e crachás ajudaria a consolidar instituições, aliado à assiduidade e ao atendimento às exigências do mercado. Vários autores já apontaram mudanças subjetivas dos catadores, ao retratarem as transformações da representação deles sobre o próprio trabalho quando suas instituições são modificadas. Porém, ocorre que não só essas mudanças institucionais, como a própria semântica positiva do lixo - caracterizada pelo conceito de reciclagem—- também acarreta mudanças subjetivas: eles passam a ter que serem mais competitivos, por exemplo. Essa semântica positiva acaba reforçando a necessidade de apoio do poder público e de reconhecimento de suas instituições, a fim de que se tornem competitivos diante dos concorrentes.

Este artigo propõe uma interconexão íntima entre os atores públicos e privados, combinada com uma divisão complementar de trabalho bem definida entre a burocracia e o catador mutuamente reconhecidos e aceitos. De modo que a semântica positiva do lixo seja algo também positivo para os catadores em vez de um desafio e que as cooperativas deixem de significar oportunismo, exploração e sejam sinônimo de adequação ao atual contexto da reciclagem. 


\section{Referênclas}

ADAMETES, C. M. O olhar da inclusão: possibilidades de pesquisa com uma catadora de lixo. Dissertação (Mestrado em Sociologia)—Universidade Estadual Paulista Júlio de Mesquita Filho, Araraquara, SP, 1998.

ALVAREZ, Sônia; DAGNINO, Evelina; ESCOBAR, Arturo. O cultural e o político nos movimentos sociais latino-americanos. In: ALVAREZ, Sônia; DAGNINO, Evelina; ESCOBAR, Arturo (Org.). Cultura e política nos movimentos sociais latino-americanos. Belo Horizonte: Ed. UFMG, 2000.

ARRUDA, R.G.L. As organizações voltadas para a coleta de recicláveis no município do Rio de Janeiro. Trabalho de conclusão de curso (Graduação)—Escola Brasileira de Administração Pública e de Empresas (Ebape), Fundação Getulio Vargas, Rio de Janeiro, 2005.

ASHFORT, B.; KREINER, G. 'How can you do it?': dirty work and the challenge of constructing a positive identity. Academy of Management Review, v.24, n.3, p.413-434, 1999.

BERTHIER, H. C. Garbage, work and society. Resources, Conservation and Recycling, n.39, p.193-210, 2003.

BIRKBECK, C. Self-employed proletarians in an Informal Factory: The Case of Cali's Garbage Dump. World Development, v. 6, n. 9/10, p. 1.173-1.185, 1979 .

BRITO, E. Programa Cooperativas de Catadores (Balanço Sintético: 1993-2000). Diretoria de Serviços Oeste. Prefeitura, Comlurb, Rio de Janeiro, fev. 2001.

CALDERONI, Sabetai. Os bilhões perdidos no lixo. 2.ed. São Paulo: Humanitas, 1998.

CARMO, M.S.; OLIVEIRA, J.A.P.; DAMASCENO, L.M.D. ARRUDA, R.G.L. A Relação Semântica do Lixo e Capital Social entre Catadores de Recicláveis Cooperados e Autônomos na Cidade do Rio de Janeiro. VII Encontro Nacional sobre Gestão Empresarial e Meio Ambiente-ENGEMA, 7., 2005, Rio de Janeiro. Anais... [S.I.: s.n.]: 2005.

DEL GAUDIO, R. Reciclagem, ação social e política de gerenciamento do lixo em São Paulo. XXVII Encontro da Associação Nacional de Pós-Graduação e Pesquisa em Administração-EnANPAD, 27., 2003, Atibaia. Anais... [S.I.: s.n.]: 2003.

DIAS, S. M. Lixo e cidadania: os impactos da política de resíduos sólidos de Belo Horizonte no mundo do trabalho do catador da Asmare. In: ENCONTRO NACIONAL DE ESTUDOS POPULACIONAIS, 13, 2002, Ouro Preto.

DOUGLAS, M. Purity and Danger: an Analysis of the Concepts of Pollution and Taboo. London, Routledge and Kegan Paul, 1966.

EIGENHEER, Emílio. Lixo, vanitas e morte: considerações de um observador de resíduos. Niterói: UFF, 2003.

FERREIRA, J. A.; ADLER, R. R. Reciclagem: mito e realidade. Rio de Janeiro. In-Folio, 2005.

EVANS, P. Government action, social capital and development: reviewing the evidence on sinergy. World Development, v.24, n.6, p. 1119-1132, 1996a.

Introduction: development strategies across the public-private divide. World Development, v. 24, n.6, p.1033-1037, $1996 \mathrm{~b}$.

GEERTZ, Clifford. A interpretação das culturas. Rio de Janeiro: Livros Técnicos e Científicos Editora S.A., 1989.

GONÇALVES, Pólita. A reciclagem integradora dos aspectos ambientais, sociais e econômicos. Rio de Janeiro: DP\&A: Fase, 2003.

INGHAM, B. The meaning of development: interactions between "new" and "old" ideas. World Development, v.21, n.11, p.1803-1821, 1993.

MAGERA, Marcio da Conceição. Os empresários do lixo: um paradoxo da modernidade-análise interdisciplinar das cooperativas de reciclagem de lixo. Campinas: Átomo, 2003.

MEDINA, M. Border scavenging: a case study of aluminum recycling in Laredo, TX and Nuevo Laredo, Mexico. Resources, Conservation and Recycling, n.23, p.107-126, 1998. 
Scavenger cooperatives in Asia and Latin America. Resources, Conservation and Recycling, n.31, p.51-69, 2000.

MEDINA, M. The World's Scavenger: Salvage for Sustainable Consumption and Production. United Kingdon, Altamira Press, 2007. NOGUEIRA, Jozeni. Viver sobre o lixo e sobreviver do lixo: um estudo com catadores de lixo em Vitória, Espírito Santo. Dissertação (Mestrado em Psicologia)—Instituto de Psicologia, Universidade Federal do Espírito Santo, Vitória, 1996.

NORTH, Douglas. Institutions, institutional change and economic performance. Cambridge: Cambridge University Press, 1990.

PORTILHO, M. F. F. Profissionais do lixo: um estudo sobre as representações sociais de engenheiros, garis e catadores. 1997. $226 f$. Dissertação (Mestrado em Psicologia)—Instituto de Psicologia, Universidade Federal do Rio de Janeiro, Rio de Janeiro, 1997.

RODRIGUES, J. C. A cultura do lixo e sua angústia. In: FALAS em torno do lixo. Rio de Janeiro: Nova/lser/Polis, 1992. p.7-11.

Higiene e ilusão: o lixo como invento social. Rio de Janeiro: NAU, 1995.

RODRIGUES, L. A globalização no lixo. O Globo, Rio de Janeiro, 13 nov. 2005. Economia, p.31-32.

SPINK, M. J. P.; MENEGON, V. M. A pesquisa como prática discursiva: superando os horrores metodológicos. In: SPINK, M. J (Org.). Práticas discursivas e produção de sentidos no cotidiano - aproximações teóricas e metodológicas. 2.ed. São Paulo: Cortez, 2000. p.63-91.

VELLOSO, M. P. Os catadores de lixo e o processo de emancipação social. Ciência \& Saúde Coletiva, v.10 (sup.), p.1-13, 2005.

VERGARA, Sylvia Constant. Projetos e relatórios de pesquisa em administração. 6.ed. São Paulo: Atlas, 2005. 